\title{
On diagnostic blocks for lumbar zygapophysial joint pain
} Nikolai Bogduk

Address: University of Newcastle, Newcastle Bone and Joint Institute, Royal Newcastle Centre, PO Box 664J, Newcastle, NSW 2300, Australia

Email: michelle.gillam@newcastle.edu.au

FI000 Medicine Reports 2010, 2:57 (doi:10.3410/M2-57)

The electronic version of this article is the complete one and can be found at: http://fl000.com/reports/medicine/content/2/57

\begin{abstract}
Diagnostic blocks are used to identify patients with back pain stemming from their lumbar zygapophysial joints. Single, diagnostic blocks have an unacceptably high false positive rate. As well, comparative local anaesthetic blocks lack validity because the prevalence of the condition is low. Relying on $50 \%$ relief following single-diagnostic blocks does not provide a valid diagnosis. Placebocontrolled blocks are the only available valid means of establishing a diagnosis of lumbar zygapophysial joint pain.
\end{abstract}

\section{Introduction and context}

The proposition that the lumbar zygapophysial joints could be a source of low back pain is valid - as a concept. In normal volunteers, experimental noxious stimulation of these joints can produce low back pain and referred pain into the lower limb [1]. The problem lies in how to establish in a given patient if their back pain stems from a zygapophysial joint. Neither medical imaging [2] nor history or physical examination [3-5] provides a means for making the diagnosis. The only method that has gained any traction is diagnostic block. Putatively painful joints can be anaesthetised directly with intraarticular blocks, or indirectly with lumbar medial branch blocks, which anaesthetise the nerves that innervate the joint [1].

Virtually all publications on the yield of intra-articular blocks did not use controls. Only one study used subcutaneous injection of normal saline as a control for intra-articular blocks [6]. For a criterion of 50\% relief of pain, the prevalence was $40 \%$; for the criterion of $90 \%$ relief of pain, it was $32 \%$.

Lumbar medial branch blocks have been more rigorously validated. They protect normal volunteers from experimentally induced pain from the zygapophysial joints [1]. They do not anaesthetise other structures that might be an alternative source of pain [1]. However, without controls, lumbar medial branch blocks have a prohibitively large false positive rate, variously reported as between $25 \%$ [7] and $41 \%[8,9]$.

One form of control comprises comparative local anaesthetic blocks, in which either a long-acting local anaesthetic or a short-acting local anaesthetic is used, on separate occasions, under double-blind conditions [10]. Comparative blocks have a sensitivity of $100 \%$ and a specificity of $65 \%$ [10].

\section{Recent advances}

At least three schools of thought and practice have arisen. One might be called the pragmatic school. It abjures controlled blocks. Moreover, it argues that it matters not whether patients obtain $50 \%$ relief or $80 \%$ relief from a diagnostic block, because their response to treatment - with radiofrequency neurotomy - is statistically indistinguishable [11]. This school maintains that imposing rigorous criteria for diagnostic blocks denies worthwhile benefit to patients who would otherwise satisfy less rigorous criteria.

Although attractive to some, the evidence for this pragmatic approach is weak. The definition of worthwhile benefit was $50 \%$ relief of pain for 6 months [11], 
which is less than the benchmark for lumbar medial branch neurotomy [12]. Nor has it been shown that 50\% relief leads to socially significant improvements in function, and elimination of other health care.

The second school insists that comparative blocks are essential, and that the criterion for a positive response be $80 \%$ relief of pain. It opposes the pragmatic school, arguing that alternative treatments, less expensive than neurotomy, can be used for patients who do not satisfy the more rigorous criteria [13]. Recently, this school argued that $80 \%$ relief was more valid than $50 \%$ relief because a greater proportion of patients with $80 \%$ relief maintained their response over 2 years [13]. However, whereas this is evidence of the stability of the response, it is not evidence of its validity.

The third school might be called the purist, or academic school. It disputes both other schools. Foremost, it argues that single diagnostic blocks are not valid because they have an unacceptably high false positive rate $[1,10]$. Consequently, patients who report either $50 \%$ or $80 \%$ relief after a single diagnostic block will include a large proportion with placebo responses. Under these conditions, the correlations reported by the pragmatic school [11] amount to no more than comparing confounded responses to a diagnostic test with questionable outcomes of treatment.

The purist school is also at odds with the second school. Comparative blocks have a sensitivity of $100 \%$ and a specificity of $65 \%$ [10], but the validity of a diagnostic test is not determined simply by its sensitivity and specificity; it is a complex product of sensitivity, specificity, and the prevalence of the condition. Table 1 illustrates the situation.

For a test with $100 \%$ sensitivity, all patients who have the condition are correctly detected. However, with a specificity of $65 \%, 35 \%$ of patients who do not have the condition report a positive result. When the prevalence is high, the number of patients who do not have the condition is low, and the number of false positive results is proportionately low. As a result, most positive responses are true positive, and the investigator can be confident that a given positive response is highly likely to be true positive. For a prevalence of $60 \%$ (Table 1), the diagnostic confidence is $81 \%$, that is, a positive result will be correct 4 times out of 5 .

As the prevalence of the condition diminishes, the number of patients who do not have the condition grows, and the number of false positive responses increases, to the extent
Table I. Outcomes of a diagnostic test illustrating how diagnostic confidence diminishes with prevalence

\begin{tabular}{lllll}
\hline Prevalence & Test & \multicolumn{2}{c}{ Condition } & $\begin{array}{c}\text { Diagnostic } \\
\text { confidence }\end{array}$ \\
\cline { 3 - 4 } & & Present & Absent & \\
\hline \multirow{2}{*}{$60 \%$} & Positive & 600 & 140 & $81 \%$ \\
& Negative & 0 & 260 & \\
& & 600 & 400 & \\
$40 \%$ & Positive & 400 & 210 & $66 \%$ \\
& Negative & 0 & 390 & \\
& & 400 & 600 & \\
& & & \\
& Positive & 200 & 280 & \\
& Negative & 0 & 520 & \\
$10 \%$ & & 200 & 800 & \\
& Positive & 100 & 315 & \\
& Negative & 0 & 585 & $15 \%$ \\
$5 \%$ & & 100 & 900 & \\
& Positive & 50 & 282 & \\
& Negative & 0 & 618 & \\
& & 50 & 950 & \\
\end{tabular}

A demonstration of the outcomes of a diagnostic test, with a sensitivity of $100 \%$ and a specificity of $65 \%$, when applied to a sample of 1000 patients, illustrating how diagnostic confidence diminishes with prevalence. Diagnostic confidence is the certainty with which the investigator can estimate that a positive result is true positive, rather than false positive, and is the number of patients who have the condition and who report a positive response, as a proportion of the total number of positive responses.

that false positive responses outnumber true positive responses. For a prevalence of $20 \%$ (Table 1), the diagnostic confidence is only $42 \%$, meaning that more than 1 in 2 positive responses will be false. For a prevalence of $5 \%$, the diagnostic confidence plummets to $15 \%$, meaning that for every 8 positive responses, 7 will be false.

This is not a problem for cervical medial branch blocks because the prevalence of cervical zygapophysial joint pain is $60 \%$ [14], and the diagnostic confidence is $81 \%$. Lumbar zygapophysial joint pain is not that common. The more favourable estimates place its prevalence at about $40 \%$; more critical estimates place it as low as $5 \%$ $[1,10]$. In the case of the former, one in three diagnoses will be wrong; in the case of the latter, seven in eight will be wrong.

For these reasons, comparative local anaesthetic blocks are not valid for the diagnosis of lumbar zygapophysial joint pain. The only means by which a practitioner can become confident that their patient actually does have lumbar zygapophysial joint pain is to perform placebocontrolled, diagnostic blocks. Without this measure, practitioners will overestimate the prevalence of lumbar zygapophysial joint pain; an inordinate number of patients will be accorded an incorrect diagnosis and be directed to inappropriate treatment, and the majority of patients treated will fail treatment. 


\section{Implications for clinical practice}

Purists demand complete relief of pain following placebo-controlled blocks. They seek to provide interventional pain medicine with a respectable, scientific basis, consonant with the standards of thought and practice in other domains of medicine. Pragmatists argue for lesser criteria, and even for the abandonment of blocks and diagnosis altogether.

The judgment lies with third-party observers. If blocks are to be disregarded, and all patients are to be treated summarily, observers cannot tell from arbitrary and random behaviour amongst practitioners. Moreover, if there is no demonstrable reduction in the burden of illness, why should they pay for this behaviour?

The evidence indicates that lumbar zygapophysial joint pain is uncommon, and under evidence-based practice lumbar medial branch neurotomy should become an uncommon procedure. In contemporary practice, however, questionable outcomes are being achieved by basing treatment on diagnostic tests that lack validity. This behaviour threatens the reputation of interventional pain medicine, and the reimbursement of its procedures.

The foremost argument against performing controlled diagnostic blocks, at least in the US, has been that insurers do not pay for controlled blocks. The consequence of such a system is that it pays for inconclusive diagnosis but abjures evidence-based, best practice. Economic modelling, however, has shown that controlled blocks are cost-effective whenever the cost of treatment exceeds the cost of blocks by a factor of 1.5 or more [15]. Whereas this might not apply in the US, it does in other jurisdictions where lumbar medial branch neurotomy is reimbursed as a neurosurgical procedure. Under those conditions, placebo-controlled blocks become mandatory, and remain cost-effective [15].

\section{Competing interests}

The author declares that he has no competing interests.

\section{References}

I. Bogduk N: Evidence-informed management of chronic back pain with facet injections and radiofrequency neurotomy. Spine J 2008, 8:56-64.

FI000 Factor 6.0 Must Read Evaluated by Wilfrid Jänig 25 Jun 2010

2. Schwarzer AC, Wang S, O'Driscoll D, Harrington T, Bogduk N, Laurent R: The ability of computed tomography to identify a painful zygapophysial joint in patients with chronic low back pain. Spine 1995, 20:907-12.

3. Manchikanti L, Pampati V, Fellows B, Baha AG: The inability of the clinical picture to characterize pain from facet joints. Pain Physician 2000, 3:158-66.

4. Laslett M, Oberg B, Aprill CN, McDonald B: Zygapophysial joint blocks in chronic low back pain: a test of Revel's model as a screening test. BMC Musculoskel Disord 2004, 5:43.

5. Laslett M, McDonald B, Aprill CN, Tropp H, Oberg B: Clinical predictors of screening lumbar zygapophysial joint blocks: development of clinical prediction rules. Spine J 2006, 6:370-9.

6. Schwarzer AC, Wang S, Bogduk N, McNaught PJ, Laurent R: Prevalence and clinical features of lumbar zygapophysial joint pain: a study in an Australian population with chronic low back pain. Ann Rheum Dis 1995, 54:100-6.

7. Schwarzer AC, Aprill CN, Derby R, Fortin J, Kine G, Bogduk N: The false-positive rate of uncontrolled diagnostic blocks of the lumbar zygapophysial joints. Pain 1994, 58:195-200.

8. Manchikanti L, Pampati V, Fellows B, Bakhit CE: Prevalence of lumbar facet joint pain in chronic low back pain. Pain Physician 1999, 2:59-64.

9. Manchikanti L, Pampati V, Fellows B, Bakhit CE: The diagnostic validity and therapeutic value of lumbar facet joint nerve blocks with or without adjuvant agents. Curr Rev Pain 2000, 4:337-44.

10. Bogduk $\mathrm{N}$ : On the rational use of diagnostic blocks for spinal pain. Neurosurg Quart 2009, 19:88-100.

II. Cohen SP, Stojanovic MP, Crooks M, Kim P, Schmidt RK, Shields CH, Croll S, Hurley RW: Lumbar zygapophysial joint (facet) joint radiofrequency denervation success as a function of pain relief during diagnostic medial branch blocks: a multicenter analysis. Spine J 2008, 8:498-504.

12. Dreyfuss P, Halbrook B, Pauza K, Joshi A, McLarty J, Bogduk N: Efficacy and validity of radiofrequency neurotomy for chronic lumbar zygapophysial joint pain. Spine 2000, 25:1270-7.

13. Manchikanti L, Pampati, Cash KA: Making sense of the accuracy of diagnostic lumbar facet joint nerve blocks: an assessment of the implications of $\mathbf{5 0 \%}$ relief, $\mathbf{8 0} \%$ relief, single block, of controlled diagnostic blocks. Pain Physician 2010, I3:।33-43.

14. Lord S, Barnsley L, Wallis BJ, Bogduk N: Chronic cervical zygapophysial joint pain after whiplash: a placebo-controlled prevalence study. Spine 1996, 2 I:1737-45.

15. Bogduk N, Holmes S: Controlled zygapophysial joint blocks: the travesty of cost-effectiveness. Pain Med 2000, I:25-34. 